\title{
FORMAÇÃO DE PROFESSORES PARA ALUNOS PÚBLICO-ALVO DA EDUCAÇÃO ESPECIAL: ALGUMAS CONSIDERAÇÕES SOBRE LIMITES E PERSPECTIVAS
}

\author{
TEACHER TRAINING FOR SPECIAL EDUCATION STUDENTS: A FEW \\ CONSIDERATIONS ABOUT LIMITATIONS AND PERSPECTIVES.
}

\author{
Aline Piccoli OTALARA ${ }^{\text {ii }}$ \\ Maria Júlia Canazza DALL'ACQUA ${ }^{\mathrm{iii}}$
}

\begin{abstract}
RESUMO: O presente trabalho procura apresentar algumas considerações acerca de questões importantes relacionadas à formação e atuação de professores no Brasil visando, no entanto, focalizar mais especificamente os desafios decorrentes da inclusão escolar em escolas regulares. Compartilhando da perspectiva de que a referida inclusão escolar poderia e deveria ser entendida como um oportunidade única para o aprimoramento tanto da própria escola como de seus atores, por meio de atividades e práticas educativas, estão apresentados elementos de análise sobre responsabilidades e atribuições de professores especialistas e também demais docentes. São ainda mencionadas informações referentes ao locus de formação e possíveis desdobramentos, seja ela inicial, continuada ou em nível de especialização que, em grande maioria, manifestam-se sob a forma de despreparo para atuar diante dos desafios do cotidiano. Nessa linha de raciocínio são apontadas algumas implicações relativas a possíveis estratégias para o aprimoramento da formação, em que sobressai o trabalho colaborativo que, contudo, ainda assim não se apresenta ausente de conflitos. Finalizando são realizadas algumas indagações acerca de mudanças de paradigmas para que, efetivamente, a educação escolar possa rumar para uma reforma sistêmica que permita redesenhar políticas de educação no contexto da inclusão escolar.
\end{abstract}

PALAVRAS-CHAVE: Educação especial. Educação inclusiva. Formação de professores.

ABSTRACT: This work aims to present a few considerations regarding important matters related to the formation and performance of teachers in Brazil. More specifically, it aims to portray the challenges originated from inclusive policies in regular schools. Analytical elements about the responsibilities and attributions of specialized teachers are presented, considering the perspective that inclusive education could and should be understood as a unique opportunity for development, not only for the school as for all its actors. Information referring to the place of formation and its implications are also mentioned, including initial formation, continued formation and specialization courses. This data often present as lack of preparation by the teachers to face the challenges they meet. Considering that, a few strategies regarding the enhancement of formation are pointed, of which the collaborative work is highlighted, although not free from conflicts. At last, some questions are raised about changes in paradigm so that school education can effectively head to a systemic renovation that would allow the reformulation of education policies in the context of school inclusion.

KEYWORDS: Special education. Inclusive education. Teacher training. 
No Brasil, em relação aos modelos de formação docente, em linhas gerais constata-se que houve a vigência de dois modelos: o primeiro voltado para formação de professores "primários" e oferecido pelas "Escolas Normais", enquanto o segundo, mantido pelas Universidades, ocupou-se com a instrução daqueles que viriam a ser, segundo denominação da época, professores "secundários", justamente aqueles que atuavam nos denominados "Cursos Normais". Esses dois modelos de formação estabeleceram-se e perduraram. Um deles voltado para conteúdos "pedagógicodidáticos", enquanto o outro para os "culturais-cognitivos", sendo que o primeiro prevaleceu nas "Escolas Normais" e o segundo nas Universidades. Sendo assim, enquanto nas Universidades considerava-se que a formação "pedagógico-didática" aconteceria naturalmente durante a prática docente, o oposto era entendido pelas "Escolas Normais", que compreendiam ser mais necessária essa forma de conhecimento para a formação do professor (SAVIANI, 2008).

Tais tendências em modelos de formação apresentadas por Saviani (2008) são confirmadas por Gatti (2010) que acrescenta que, para os cursos de licenciatura, mesmo no século XXI, o ensino de conteúdos disciplinares específicos da formação para a docência continua negligenciado pelas Universidades. Neste sentido, a autora observa que nos cursos de Pedagogia há uma predominância de disciplinas voltadas para os fundamentos teóricos da educação, enquanto que nas licenciaturas privilegiam-se as disciplinas especificas das áreas, em detrimento daquelas voltadas à prática do professor como, por exemplo, na disciplina de didática geral. E constata também que a quantidade de disciplinas obrigatórias e optativas voltadas para a formação "pedagógico-didática" é mínima e que, mesmo nessas, há um desequilíbrio entre teorias e práticas, favorecendo as "teorizações mais abstratas".

Sendo assim, essa tendência da formação inicial mais voltada para fundamentos teóricos é citada por Lima (2002, p.227):

Dado seu caráter excessivamente acadêmico, os cursos de formação inicial de professores têm sido alvo de duras críticas. Eles são acusados de ignorar os conhecimentos práticos dos professores, de estar associados a abordagens transmissivas e tecnológicas, de ter pequena incidência no trabalho realizado pela escola, de ser responsáveis pela transmissão de conhecimentos interpretados como objetivos, absolutos, indiscutíveis, ignorando a concepção que os tem como problemáticos, provisórios, construídos social e historicamente, sujeitos a influências de diversas ordens, dentre outras tantas críticas. 
Ainda segundo Lima (2002), pesquisas mostram que os conhecimentos abordados durante a formação inicial têm poucas chances de serem introduzidos pelos futuros professores em sua prática. Nesse sentido, e agora enfocando especificamente a escolarização de alunos com deficiências, oito anos depois Parizzi e Reali, quanto à formação inicial, afirmam que:

\begin{abstract}
Os modelos de formação de professores para a Educação Especial não acompanharam as especificidades que o ensino nessa área foram exigindo ao longo do tempo: seja em termos de promover nos professores conhecimentos para a crítica e implementação de modelos mais adequados de atendimento, seja em termos de desenvolver nesses profissionais competências mais adequadas para o atendimento pleno das necessidades educacionais dos alunos. (PARIZZI e REALI 2010, p.77)
\end{abstract}

De acordo com Gatti (2010), também o número de disciplinas com temáticas voltadas à Educação Especial mostra-se incipiente, totalizando em média 3,8\% de todas as oferecidas. Já em relação aos estágios, que poderiam fornecer alguma experiência sobre a prática, a citada autora ainda encontrou poucas informações, e também imprecisões, que impediram o aprofundamento da análise sobre esse aspecto da formação inicial. O estágio é um exemplo que poderia contribuir para a formação inicial dos professores, dado que poderia estabelecer um elo entre a formação teórica e a prática, embora o aprendizado da profissão docente deva acontecer durante toda carreira do professor.

Nesse sentido, no contexto da inclusão escolar de alunos público-alvo da educação especial (PAEE), Capellini e Rodrigues (2009), afirmam que essa referida inclusão escolar deveria ser entendida como uma oportunidade de enriquecimento das atividades e práticas educativas, trazendo avanços tanto para todos os alunos como também para os professores. Prieto $(2010$, p.58) acrescenta que os “[...] conhecimentos sobre o ensino de alunos com necessidades educacionais especiais não podem ser de domínio apenas de alguns 'especialistas' e, sim, apropriado pelo maior número possível de profissionais da educação, idealmente por todos." No entanto, ao valorizar as diferenças como ponto essencial para a inclusão, ainda assim faz-se necessário não abrir mão do conhecimento sobre o próprio processo de inclusão e sobre as especificidades do ensino para esse público. Por isso, tratar os conhecimentos acerca das pessoas com deficiência somente como um tema optativo para os alunos de licenciatura e Pedagogia 
pode ser insuficiente para que o processo de inclusão se efetive, pois, segundo Oliveira e Silva (2008, p.47):

O estereótipo do 'aluno-padrão' idealizado não é desfeito na formação do professor. A escola como uma instituição social composta por normas, currículo, conteúdo, metodologia, avaliação e regulamento pré-estabelecidos, apresenta níveis de comportamentos esperados, o que constitui um ideal pedagógico. Assim temos como aluno ideal um sujeito capaz e como aluno não ideal o sujeito incapaz.

Dentre os documentos oficiais que apontam para a necessidade de qualificação de recursos humanos encontra-se o Plano Nacional de Educação (BRASIL, 2000, p.65), no qual se lê "Não há como ter uma escola regular eficaz quanto ao desenvolvimento e aprendizagem dos educandos especiais sem que seus professores, demais técnicos, pessoal administrativo e auxiliar sejam preparados para atendê-los adequadamente [...]" enfatiza-se a necessidade de instrução a preparação de todos os professores para o ensino de alunos com deficiência.

Já o Decreto no 7.611 (BRASIL, 2011) que versa "sobre a educação especial, o atendimento educacional especializado e dá outras providências", prevê a garantia de um sistema educacional inclusivo em todos os níveis, a aplicação de recursos federais, a oferta de atendimento especializado e recursos para a acessibilidade para fomentar o desenvolvimento de recursos didáticos e pedagógicos que eliminem as barreiras no processo de ensino e aprendizagem e a formação de professores, gestores, educadores e demais profissionais da escola para a educação na perspectiva da educação inclusiva.

Contudo, marcando forte distanciamento entre o que foi objeto de legislação e a prática, pesquisas panorâmicas como a realizada por Bueno (2002) auxiliam no sentido de verificar e explicitar dados relevantes sobre a implantação da temática da inclusão de alunos com deficiências nos cursos de licenciatura para o Ensino Básico. Segundo esse autor, dos cursos de licenciatura (formação de professores para o ensino do $5^{\circ}$ ao $8^{\circ}$ anos do Ensino Fundamental e Ensino Médio) das cinquenta e oito universidades que fizeram parte do universo pesquisado, apenas onze ofereciam disciplinas sobre Educação Especial. Das dezesseis disciplinas mencionadas 6 eram definidas como obrigatórias e as outras dez eram eletivas.

No entanto é preciso pensar se a inserção de disciplinas específicas seria suficiente para dar conta da formação inicial de professores para uma escola inclusiva ou se, ao invés disso, seria necessário um trabalho interdisciplinar. Sob outra 
perspectiva, Rodrigues (2006) aponta que somente a prática em serviço, continuada, reflexiva e coletiva seria capaz de formar professores para a educação inclusiva e, segundo o autor, é por esse motivo que mesmo tendo recebido em sua formação inicial disciplinas específicas, os professores se dizem ainda despreparados.

Apesar das discussões sobre a introdução ou não de disciplinas específicas, o fato é que existe uma necessidade de melhoria da formação inicial de professores para o trabalho em uma escola inclusiva pois, conforme aponta outro estudo sobre a formação de professores, agora de Vioto e Vitaliano (2011), os formandos do curso de Pedagogia da Universidade Estadual de Londrina (UEL) não se sentiam preparados para atuar com alunos com "necessidades educacionais especiais (NEE)", segundo terminologia empregada na época, após sua formação inicial no curso. A conclusão foi a de que "Todos os participantes da pesquisa consideraram que o curso de Pedagogia (currículo de 2005) apresenta muitas lacunas quanto à formação para inclusão de alunos com NEE" (VIOTO; VITALIANO, 2011, p.01). E, em relação à formação inicial para o trabalho inclusivo, Tinos, Orlando e Denari, (2008, p.205) mostram que os alunos de dois cursos de graduação em Pedagogia indicaram:

[...] a necessidade de conviver, aprender e estudar mais sobre as categorias de deficiências como forma de se eliminar preconceitos, preparar-se para o trabalho de sucesso com pessoas deficientes e ter condições de refletir e construir críticas acerca das políticas de ações implantadas.

Outro estudo de Vitaliano (2007), que agora enfoca a formação dos professores de cursos de licenciatura atuantes na Universidade Estadual de Londrina (UEL), indica que eles também não se sentiam preparados para trabalhar com alunos com deficiências. Segundo a autora, $84,2 \%$ dos cento e setenta e oito professores entrevistados e atuantes em treze cursos de licenciatura na UEL, disseram não ter conhecimento suficiente para incluir alunos com "necessidades educacionais especiais" e 63\% deles indicou ter interesse em participar de um programa de formação.

Caiado, Jesus e Baptista (2011, p.9) apontam que muitas pesquisas “[...] buscam considerar a tensão: a formação inicial de professores e a perspectiva da Educação Inclusiva. " Os autores referem-se ao assunto como uma tensão pelas dificuldades apontadas por diversas pesquisas realizadas em diferentes partes do país como, por exemplo, Espírito Santo, Rio Grande do Sul, Rio Grande do Norte e Paraná, o que 
demonstra que o tema merece atenção no sentido de busca de caminhos para resolução dos problemas apresentados pelos estudos.

Assim como foi apontado nas pesquisas sobre a formação inicial de professores, também a formação continuada é necessária para o processo de inclusão das pessoas com deficiência, pois, como afirmam Silva e Boas (2012, p.126) a:

Discrepância entre o que está previsto em lei e o que asseveram os professores atuantes em salas regulares revela que a formação continuada do professor, com vistas a garantir um ensino de qualidade a todos os alunos da escola regular, é algo que ainda precisa ser tomado como uma necessidade real e imediata.

Corroborando com essa afirmação encontra-se, por exemplo, um estudo de Sant'Ana (2005) que, por meio das análises que fez sobre as concepções de professores e diretores de escolas públicas de Ensino Fundamental sobre a Escola Inclusiva, verificou que há indicação de que uma das principais dificuldades apontadas por eles também foi a necessidade de formação.

Nesse sentido, encontra-se ainda a pesquisa de Capellini e Rodrigues (2009), realizada por meio da aplicação de questionários semiestruturados respondidos por 423 professores, que demonstra que esses apontavam tanto a formação inicial quanto a continuada como necessária para minimizar as dificuldades do processo de inclusão de pessoas com deficiência nas escolas regulares.

Manzini (2007) ressalta que são recorrentes as pesquisas que afirmam que os professores se sentem despreparados para a inclusão de alunos com deficiência em suas classes e que, portanto, é preciso atentar para que se realizem trabalhos científicos que tragam novos conhecimentos para a área.

A formação de professores, seja no âmbito da formação inicial ou continuada, demanda aprimoramentos e as linhas de enfrentamento disso têm acontecido de diferentes formas e por meio de diferentes estratégias como, por exemplo, via educação a distância $(\mathrm{EaD})$ e especializações. Nesse sentido, em uma pesquisa que se debruçou sobre a formação à distância como modalidade em expansão para professores em geral e especialistas em particular, Moreira (2012) alerta para o esvaziamento que essa opção pode representar. Num quadro de análise aprofundado, à luz do que identificou com os participantes de sua pesquisa, expõe as implicações decorrentes dessa mudança de perspectiva e alerta que, no contexto brasileiro, 
[...]há ainda na $\mathrm{EaD}$ a forte presença da certificação, juntamente com a perspectiva exagerada de que a especialização de educação especial dará as principais respostas ou 'receitas' sobre o como proceder frente às dificuldades vivenciadas no cotidiano dos professores, especialmente preocupados com o desenvolvimento da inclusão no contexto escolar. Para além desta percepção pragmática, vinculada ao curso, também há a questão teórica, uma vez que os participantes afirmam que o mesmo é de base epistemológica e não empírica, instaurando-se aqui um sentimento de "frustração" nos alunos. Além do exposto, em razão da ausência de solidez em nível de formação inicial, o curso de especialização não pode aprofundar os pressupostos epistemológicos selecionados, uma vez que os alunos não têm constructos acadêmicos capazes de acompanhar este processo de aprofundamento, pois têm percepções ainda elementares frente ao processo de inclusão entre outras questões relacionadas a conhecimentos mais específicos sobre as várias deficiências. (MOREIRA, 2012, p. 313)

Numa outra perspectiva, visando aprimorar a formação daqueles que se voltam para a atuação junto a alunos considerados do âmbito da Educação Especial, em meio às estratégias possíveis para formação está o trabalho colaborativo entre pesquisadores e professores, conforme explicita Marques (2012, p.16),

Os processos de formação continuada que incorporem os professores como um parceiro e responsável pela sua formação, é uma tendência que se coloca para responder aos fracassos observados na formação continuada que tem sido desenvolvida até o momento.

Segundo Lima (2002), na colaboração, cada indivíduo participa com a sua parte num empreendimento comum cujo resultado beneficia todas as pessoas envolvidas e todos participam das decisões e têm responsabilidades sobre esse processo.

Porém, embora desejável, tal mudança de perspectiva não se mostra de maneira linear e ausente de conflitos. Já em um trabalho pioneiro de Capellini (2004), que foi citado por Fontes (2009), a pesquisadora

[...] discute a mudança na formação inicial e continuada dos professores do ensino comum e especial, a fim de prepará-los parta atuarem em colaboração. Discute-se ainda a redefinição do papel do professor de Educação Especial para atuar como apoio às atividades desenvolvidas em classes comuns e não comente em serviços especializados. (FONTES, 2009, p. 78) 
E completa, ainda, mencionando que a colaboração

[...] nem sempre é uma experiência positiva para os professores, dado que se sentem desconfortáveis com a presença de outro professor em sala de aula. Grande parte desta dificuldade deve-se ao fato de que esse tipo de ensino exige uma harmonia de ações entre professores com formações diferentes. Além disso, demanda um certo tempo para que laços de confiança se estabeleçam. (FONTES, 2009, p. 78)

A esse cenário acresce-se o fato de que após 2006, portanto há uma década, abre-se o leque de possibilidades formativas que,

[...] desde então passa a se dar em cursos de licenciatura que formam professores para atuar exclusivamente na educação especial, em cursos de atualização e de extensão e, em grande parte, em cursos de especialização, nível de pós-graduação lato sensu. (MIRANDA, 2013, p. 45)

Assim, é possível perceber a necessidade da formação de professores, seja inicial ou continuada, para lidar com os desafios da inclusão escolar de alunos com deficiência no ensino regular, além de também ser possível visualizar a colaboração enquanto uma possibilidade para mediar esses processos de formação.

Mas, por onde começar? De onde partir?

Numa escola que se baseia na classificação e na hierarquização que conformam a cultura escolar, que agrupa por similaridades e que adota a rigidez como regra, como pensar em mudanças cristalizadas ao longo do tempo? Como professores que sempre atuaram sozinhos diante de grupos de alunos, mais ou menos numerosos, podem começar a pensar em colaboração docente? Como conceber que o aluno que tradicionalmente não estava presente nas salas de aula, passe a estar? São mudanças de paradigmas.

Nessa linha de raciocínio, segundo Skrtic (2014), ambientes menos restritivos, avaliações não discriminatórias, são alguns pontos que mereceriam atenção. Para esse autor faz-se necessária uma reforma sistêmica, que permita redesenhar políticas de Educação. 


\section{Referências}

BRASIL. Plano nacional de educação. Brasília, DF, 2000. Disponível em: <http://portal.mec.gov.br/arquivos/pdf/pne.pdf>. Acesso em: 04 jul. 2012.

Decreto $n^{\circ} 7.611$, de 17 de novembro de 2011. Dispõe sobre a educação especial, o atendimento educacional especializado e dá outras providências. Diário

Oficial da União, Brasília, DF, 17 nov. 2011. Disponível em: <http://www.planalto.gov.br/ccivil_03/_Ato2011-2014/2011/Decreto/D7611.htm>. Acesso em: 08 fev. 2014.

BUENO, J. G. S. A educação especial nas universidades brasileiras. Brasília: Ministério da Educação, Secretaria de Educação Especial, 2002.

CAIADO, K. R. M.; JESUS, D. M. de; BAPTISTA, C. R. (Org.). Professores e educação especial. Porto Alegre: Mediação, v.1, 2011.

CAPELLINI, V. L. M. F. Avaliação das possibilidades do ensino colaborativo no processo de inclusão escolar do aluno com deficiência mental. 333f. Tese (Doutorado em Educação Especial). Universidade Federal de São Carlos, São Carlos, 2004.

CAPELLINI, V. L. M. F.; RODRIGUES, O. M. P. R. Concepções de professores acerca dos fatores que dificultam o processo da educação inclusiva. Revista Educação, Porto Alegre, v.32, n.3, p.355-364, set./dez. 2009.

FONTES, R. de S. Ensino Colaborativo: uma proposta de educação inclusiva. Araraquara, SP: Junqueira\&Marin, 2009.

GATTI, B. A. Formação de professores no Brasil: características e problemas. Educação e Sociedade, Campinas, v.31, n.113, p.1355-1379, out.-dez. 2010. Disponível em: <http://www.scielo.br/pdf/es/v31n113/16.pdf>. Acesso em: 07 abr. 2014.

LIMA, J. Á de. As culturas colaborativas nas escolas: estruturas, processos e conteúdos. Porto: Porto Editora, 2002.

MANZINI, E. J. Que tipo de conhecimento as pesquisas de pós-graduação têm fornecido sobre inclusão? In: JESUS, D. M. de; BAPTISTA, C. R.; BARRETO, M. A. S. C.; VICTOR, S. L. (Org.). Inclusão práticas pedagógicas e trajetórias de pesquisa. Porto Alegre: FACITEC, 2007.

MARQUES, R. N. Formação continuada de professores em uma perspectiva da interação formador-formando. 2012. 116 f. Tese (Doutorado em Educação Escolar) Universidade Estadual Paulista, Faculdade de Ciências e Letras, Araraquara, 2012.

MIRANDA, M. J. C., et al. Inclusão, educação infantil e formação de professores. Marília: Oficina Universitária; São Paulo: Cultura Acadêmica, 2013. 
OLIVEIRA, A. S. S.; SILVA, N. C. B. da. Inclusão escolar e formação de professores: a resignificação da escola e sociedade. In: DENARI, F. E. Igualdade, diversidade e educação (mais inclusiva). São Carlos: Pedro \& João Editores, 2008.

MOREIRA, M. H. B. Educação Especial e Educação: percepções sobre a formação docente em nível de pós-graduação - EaD em São Paulo e em Lisboa. 350f. Tese (Doutorado em Educação Escolar). Universidade Estadual Paulista Júlio de Mesquita Filho, Araraquara, 2012.

PARIZZI, R. A.; REALI, A. M. de M. R. Práticas pedagógicas de professores de educação especial: desafios impostos pela diversidade. In: MIZUKAMI, M. da G. N.; REALI, A. M. de M. R. (Orgs.). Aprendizagem profissional da docência: saberes, contextos e práticas. São Carlos: EdUFSCar, 2010.

PRIETO, R. G. Políticas de inclusão escolar no Brasil: sobre novos / velhos significados para educação especial. In: MENDES, E. G.; ALMEIDA, M. A. (Org.). Das margens ao centro: perspectiva para as políticas e práticas educacionais no contexto da educação especial inclusiva. Araraquara: Junqueira\&Marin, 2010.

RODRIGUES, D. Dez ideias (mal)feitas sobre a educação inclusiva. In: RODRIGUES, D. (Org.). Inclusão e educação: doze olhares sobre a educação inclusiva. São Paulo: Summus, 2006.

SANT'ANA, I. M. Educação inclusiva: concepções de professores e diretores. Revista Psicologia em Estudo, Maringá, v.10, n.2, p. 227-234, maio/ago. 2005. Disponível em: <http://www.scielo.br/pdf/pe/v10n2/v10n2a09.pdf>. Acesso em: 25 nov. 2013.

SAVIANI, D. A pedagogia no Brasil: história e teoria. Campinas: Autores Associados, 2008. (Coleção Memória da Educação).

SILVA, S. P. da; BOAS, D. C. V. Perspectivas de professores de salas regulares acerca da inclusão de alunos com surdocegueira. In: SEABRA JÚNIOR, M. O.; CASTRO, R. M. de; (Org.). Avaliação, formação docente e perspectivas da educação inclusiva: eixo do atendimento educacional especializado. Marília: Oficina Universitária; São Paulo: Cultura Acadêmica, 2012.

SKRTIC, T. M. A injustiça institucionalizada: construções e usos da deficiência na escola. In: BUENO, J. G. S.; MUNAKATA, K.; CHIOZZINI, D. F. (Orgs.) A escola como objeto de estudo: escola, desigualdades, diversidades. Araraquara, SP: Junqueira\&Marin, 2014.

TINOS, L. M. S.; ORLANDO, P. D.; DENARI, F. E. Graduandos de Pedagogia e suas concepções sobre a educação inclusiva. In: DENARI, F.E. Igualdade, diversidade e educação (mais inclusiva). São Carlos: Pedro \& João Editores, 2008.

VIOTO, J. R. B.; VITALIANO, C. R. Formação inicial de professores e o processo de educação inclusiva. In: CONGRESSO NACIONAL DE PSICOLOGIA ESCOLAR E EDUCACIONAL, 10. 2011, Maringá. Anais... Maringá: Universidade Estadual de Maringá, 2011. 
VITALIANO, C. R. Análise da necessidade de preparação pedagógica de professores de cursos de licenciatura para inclusão de alunos com necessidades educacionais especiais. Revista Brasileira de Educação Especial, Marília, v.13, n.3, p.399-414, 2007.

\section{Como referenciar este artigo}

OTALARA, Aline Piccoli.; DALL'ACQUA, Maria Júlia Canazza. Formação de professores para alunos público-alvo da educação especial: algumas considerações sobre limites e perspectivas. Revista Ibero-Americana de Estudos em Educação, v. 11, n. esp. 2, p.1048-1058, 2016. Disponível em: <https://dx.doi.org/10.21723/riaee.v11.esp2.p1048-1058>. E-ISSN: 1982-5587.

\section{Sobre os autores}

i Artigo elaborado com base em parte da Tese intitulada "A formação de professores para o trabalho com deficientes visuais: uma experiência inicial de colaboração a partir do desenvolvimento de materiais didáticos", defendida por Aline Piccoli Otalara, sob orientação da Profa. Dra. Maria Júlia Canazza Dall'Acqua

ii Doutora pela Universidade Estadual Paulista "Júlio de Mesquita Filho, Campus de Araraquara, pelo Programa de Pós-graduação em Educação Escolar. E-mail: alinepo@uol.com.br

iii Profa. Dra. aposentada da FCL/UNESP/CAr, atuando junto ao Programa de Pós-graduação em Educação Escolar da FCL. E-mail: juliacandal@ gmail.com 